\title{
Nanoparticles Decorated on Resin Particles and Their Flame Retardancy Behavior for Polymer Composites
}

\author{
Nour F. Attia ${ }^{1}$ and Mohamed Zayed ${ }^{2}$ \\ ${ }^{1}$ Fire Protection Laboratory, National Institute for Standards, P.O. Box 136, Giza 12211, Egypt \\ ${ }^{2}$ Chemistry Department, Faculty of Science, Cairo University, Nahdet Misr Street, Giza 12613, Egypt \\ Correspondence should be addressed to Nour F. Attia; drnour2005@yahoo.com
}

Received 14 March 2017; Accepted 19 June 2017; Published 19 July 2017

Academic Editor: Jim Low

Copyright (c) 2017 Nour F. Attia and Mohamed Zayed. This is an open access article distributed under the Creative Commons Attribution License, which permits unrestricted use, distribution, and reproduction in any medium, provided the original work is properly cited.

\begin{abstract}
New nanocomposites have been developed by doping of amberlite IR120 resin with spherical $\mathrm{TiO}_{2}$ nanoparticles in the presence of maleate diphosphate. Polystyrene composites of resin, maleate diphosphate, and resin-maleate diphosphate were prepared individually. This is in addition to preparation of polymer nanocomposites of polystyrene-resin doped $\mathrm{TiO}_{2}$ nanoparticles-maleate diphosphate. The flame retardancy and thermal stability properties of these developed polymer composites were evaluated. The inclusion of resin and resin doped nanoparticles improved the fire retardant behavior of polystyrene composites and enhanced their thermal stability. Synergistic behavior between flame retardant, resin, and nanoparticles was detected. The rate of burning of the polymer nanocomposites was recorded as $10.7 \mathrm{~mm} / \mathrm{min}$ achieving $77 \%$ reduction compared to pure polystyrene ( $46.5 \mathrm{~mm} / \mathrm{min})$. The peak heat release rate (PHRR) of the new polymer composites has reduced achieving $46 \%$ reduction compared to blank polymer. The morphology and dispersion of nanoparticles on resin and in polymer nanocomposites were characterized using transmission and scanning electron microscopy, respectively. The flame retardancy and thermal properties were evaluated using UL94 flame chamber, cone tests, and thermogravimetric analysis, respectively.
\end{abstract}

\section{Introduction}

The interesting properties of thermoplastic polymers made them demanded in various applications. However, their poor thermal and bad flammability properties restrict some of their applications. One of these thermoplastic polymers is polystyrene (PS) which is inexpensive polymer and has characteristic features which are required in various industrial applications such as packaging, appliances, electronic, automobile, and electrical applications [1]. So, the study to enhance its thermal stability and flame retardancy properties is required and highly demanded. Usually to improve the thermal stability and flame resistance of thermoplastic polymers flame retardant materials have to be used as additives $[2,3]$. Halogen-based flame retardants were used and these materials were found to be effective for flame retardation; however these materials were inhibited due to their associated environmental pollution [4-6]. There are tremendous efforts to find alternative effective flame retardant materials to replace halogenated ones. Phosphorus containing flame retardants has been used which was based on condensed phase action through char forming effect $[7,8]$. Also, metal hydroxides have been used as flame retardants additives but their high effective loading was attributed to poor dispersion and drawbacks in mechanical properties of polymer composites $[9,10]$. Furthermore, the use of combination of charring agent, blowing agent, and acid source termed as intumescent flame retardant achieved good flame retardancy of polymer composites and low toxic gas emission [11-13]. On the other hand, various aluminosilicates have been used as flame retardants fillers such as montmorillonites [14], halloysite nanotubes [15], and zeolites [16]. These materials were used alone and in conjunction with other conventional flame retardant materials as synergistic fillers $[17,18]$. Interestingly, there are research trend to find alternative potential synergistic additive with intumescent flame retardant systems $[17,19]$. This is 
in addition to the use of other various nanomaterials as flame retardant fillers such as organoclay [20], metal oxide nanoparticles [21], carbon nanotubes [22], and graphene sheets [23]. These materials improved the mechanical and flame resistance properties of polymer nanocomposites. In our recent investigations, graphene sheets, organic nanoparticles, metal hydroxide nanoparticles, and polymer nanofibers have been used as flame retardant for polymer nanocomposites [24-27]. This is in conjunction with flammability study of various textile fabrics $[28,29]$. This is in conjunction with our experience in synthesis and characterization of various nanomaterials [30]. In this study, we report for the first time novel one pot method for the synthesis of Amberlite IR120 resin- (AR-) phosphorus based flame retardant system. This involved the decoration of $\mathrm{AR}$ with $\mathrm{TiO}_{2}$ nanoparticles $\left(\mathrm{TiO}_{2} \mathrm{NPs}\right)$ of an average particle size of $21 \mathrm{~nm}$ in presence of maleate diphosphate as flame retardant (FR). The effect of functionalization $\mathrm{AR}$ with $\mathrm{TiO}_{2} \mathrm{NPs}$ on the flammability and thermal stability of polystyrene nanocomposites was studied. Furthermore, the flame retardancy properties of polymer composites of AR and maleate diphosphate separately and together have investigated.

\section{Experimental}

2.1. Materials. Polystyrene with a grade $15 \mathrm{NF}$ for injection molding was purchased from LG Chem, Korea. Diethyl maleate was supplied by Merck, Schuchardt OHG 85662 hohenbrun, Germany. Amberlite IR120 resin was obtained from Sigma Aldrich Chemie GMBH, Germany. $\mathrm{TiO}_{2}$ nanoparticles with an average diameter of $21 \mathrm{~nm}$ and chloroform were purchased from Sigma Aldrich Chemie GMBH, Germany.

2.2. Synthesis of Flame Retardant (FR) Material. The maleate diphosphate was prepared according to previous report [31]. In this synthesis, in a round bottom flask 1 and 2 moles of diethyl maleate and phosphoric acid, respectively, were mixed and refluxed for $4 \mathrm{~h}$ at $120^{\circ} \mathrm{C}$ and, then, filtered and cooled at room temperature and coded as FR.

2.3. Synthesis of Resin-FR Composites and Resin-TiO ${ }_{2} \mathrm{NP}-\mathrm{FR}$ Nanocomposites. In a ceramic capsule of ball milling machine containing various zirconium oxide balls equal mass of AR and FR was added. Then, suitable volume of chloroform was added to the previous mixture. Afterwards, the ball milling machine rotated at $300 \mathrm{rpm}$ for $12 \mathrm{~h}$ resulting in AR-FR composite. The previous mixture was repeated with replacing 5 and 10 wt $\%$ of AR with $\mathrm{TiO}_{2}$ nanoparticles, separately. Then, the ball milling machine was rotated at the same rpm for the same time period producing nanocomposites $\mathrm{AR}-\mathrm{TiO}_{2} \mathrm{NP}-$ FR-5 and AR-TiO 2 NP-FR-10 based on AR mass.

2.4. Synthesis of Polystyrene Composites. In PS solution dissolved in chloroform, we disperse $30 \mathrm{wt} \%$ of FR and AR based on final mass of the composites separately forming 30\% composite of PS-FR and PS-AR, respectively. Then, mechanically stirred for 3 hours, afterwards the solvent was evaporated.
In PS solution the composites FR-AR, $\mathrm{AR}-\mathrm{TiO}_{2} \mathrm{NP}-\mathrm{FR}-5$, and $\mathrm{AR}-\mathrm{TiO}_{2} \mathrm{NP}-\mathrm{FR}-10$ were mixed separately. Then, the mixtures were stirred for the same time afterwards; the solvent was evaporated and the samples were compressed and molded at $180^{\circ} \mathrm{C}$ for $10 \mathrm{~min}$ at 100 tones. Also virgin PS sample was molded as blank.

2.5. Characterization. FT-IR spectroscopic analysis was performed using a Nicolet 380 spectrophotometer (Thermo Scientific) in the wave number range $400-4000 \mathrm{~cm}^{-1}$. Thermogravimetric analysis was carried out using TGA 50 (TA Shimudzu, Inc.) under nitrogen atmosphere. The SEM images were then taken using a scanning electron microscope (Quanta FEG-250, operating at a voltage of $10 \mathrm{kV}$ ). TEM images were obtained using a JEOL (JEM-1400 TEM) with an accelerating voltage of $100 \mathrm{kV}$. The flammability properties of various composites and blank samples were conducted using flame chamber (UL94) by horizontal test according to IEC 60695-11-10 [32]. Furthermore, the flammability properties were investigated using cone calorimeter (Fire Testing Technology) according to ISO 5660-1 [33]. The properties obtained were peak heat release rate (PHRR), total heat release rate (THR), and average effective heat of combustion (AEHC). This is in addition to average mass loss rate (AMLR), time to ignition $\left(t_{\text {ign }}\right)$, average heat release rate (AHRR), and emission of $\mathrm{CO}$ and $\mathrm{CO}_{2}$ gases.

\section{Results and Discussion}

3.1. Structural Characterization of Resin-Flame Retardant Composites and Resin-TiO ${ }_{2} \mathrm{NP}-\mathrm{FR}$ Nanocomposites. Firstly the FR material (maleate diphosphate) used in the synthesis process was synthesized based on previous report [31]. The structure of the FR was confirmed using FT-IR spectroscopy. Figure 1 reflects the characteristic absorption bands of FR. The absorption band positioned at $1024 \mathrm{~cm}^{-1}$ can be attributed to $\mathrm{C}-\mathrm{O}-\mathrm{P}$ stretching vibrations. The absorption band suited at $1718 \mathrm{~cm}^{-1}$ corresponds to $\mathrm{C}=\mathrm{O}$ stretching vibrations of ester [31]. The absorption band detected at $1638 \mathrm{~cm}^{-1}$ is related to the $\mathrm{C}=\mathrm{C}$ stretching vibrations. Moreover, the absorption band located at $1305 \mathrm{~cm}^{-1}$ is specified to $\mathrm{P}=\mathrm{O}$ stretching [31]. Interestingly, the absorption bands appear at 2984 and $2794 \mathrm{~cm}^{-1}$ are assigned to symmetrical and asymmetrical absorption of the $\mathrm{C}-\mathrm{H}$ group. The band observed at $3426 \mathrm{~cm}^{-1}$ can be related to the $\mathrm{O}-\mathrm{H}$ stretching vibrations [31].

Facile and effective method has been developed for the synthesis of AR-FR composites and AR particles were decorated with $\mathrm{TiO}_{2}$ NPs producing new flame retardant system. The AR-FR composite was prepared by mixing of AR and FR together in ball mill capsule filled with zirconium oxide balls. During the milling process the FR molecule wrapped AR surface. This was derived by the mechanochemical energy created from the collision between zirconium oxide balls and walls of capsule and with AR particles during milling process. Using the same process AR was doped with $\mathrm{TiO}_{2} \mathrm{NPs}_{\text {of }}$ average particle size of $21 \mathrm{~nm}$. The $\mathrm{TiO}_{2} \mathrm{NPs}$ were dispersed on the surface of AR and then wrapped by FR which aid the 


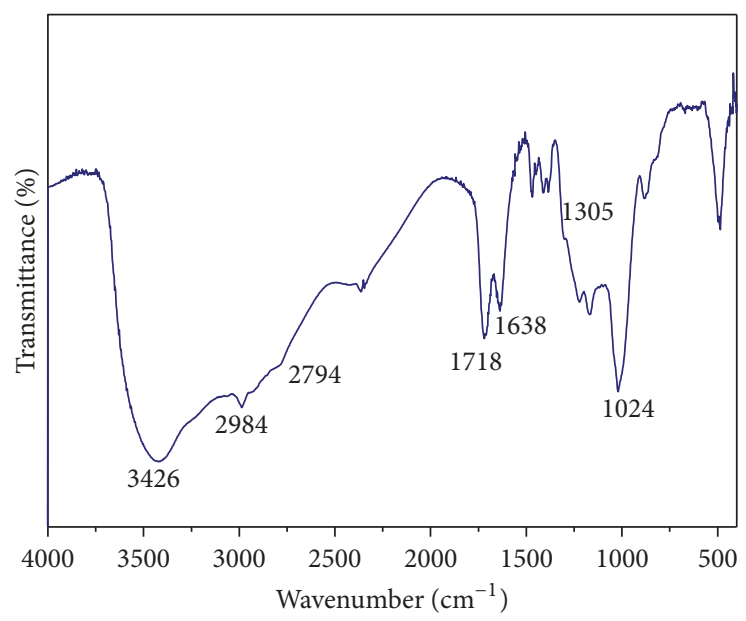

FIGURE 1: FTIR spectra of maleate diphosphate (FR).

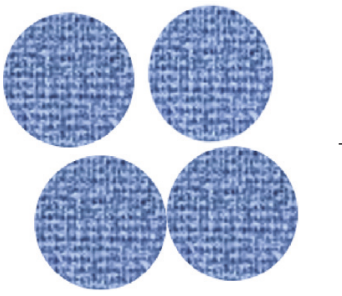

AR

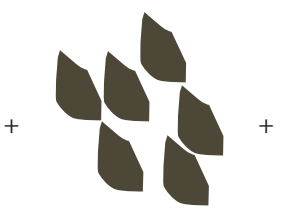

FR

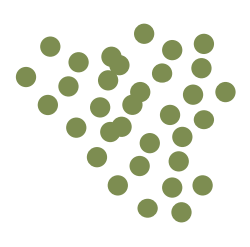

$\mathrm{TiO}_{2} \mathrm{NPs}$

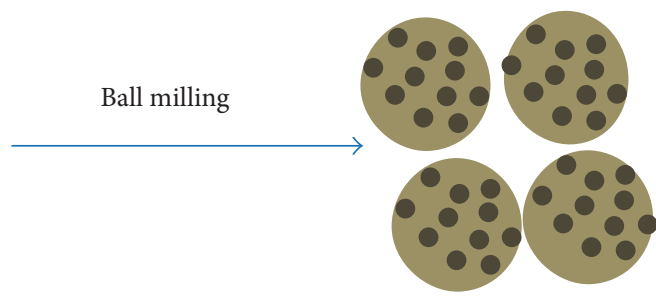

$\mathrm{AR}-\mathrm{TiO}_{2} \mathrm{NP}-\mathrm{FR}$

FIGURE 2: Schematic diagram showing the synthesis of resin doped $\mathrm{TiO}_{2} \mathrm{NP}-\mathrm{FR}$ nanocomposites.

doping process. The synthesis process was represented by the schematic diagram in Figure 2.

On the other hand, the morphology of the AR and $\mathrm{TiO}_{2}$ NPs individually and their decorated form was investigated using microscopic techniques. Figure 3(a) shows the TEM image of AR which has spherical shape and in micrometer range. However, $\mathrm{TiO}_{2} \mathrm{NPs}$ were found in aggregated form of a spherical shape with an average particle diameter of $21 \mathrm{~nm}$ as seen in SEM image (Figure 3(b)). The $\mathrm{TiO}_{2} \mathrm{NPs}$ have doped AR particles in well dispersed form as shown in Figures 3(c) and 3(d); then, the doped $\mathrm{TiO}_{2} \mathrm{NPs}$ were wrapped by FR (Figure 3(d)). It is important to note that the ball milling process dispersed the aggregated form of $\mathrm{TiO}_{2} \mathrm{NPs}$ which produced dispersed form of nanoparticles on the AR surface as seen in Figure 3(d).

3.2. Resin-TiO ${ }_{2} \mathrm{NP}-\mathrm{FR}$ Based Polystyrene Nanocomposites.

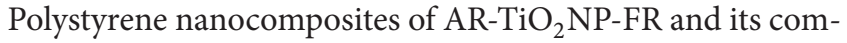
posites with AR-FR, AR, and FR have been prepared individually through solvent blending method. The morphology of the nanocomposites was characterized using SEM. The dispersion of AR doped with nanoparticles in polymer matrix was elucidated by SEM images. Figure 4(a) shows the SEM image of blank PS. Figure 4(b) represents the morphology of PS-AR-TiO ${ }_{2}$ NP-FR-5 which clearly shows the well dispersion of $\mathrm{AR}-\mathrm{TiO}_{2} \mathrm{NP}-\mathrm{FR}$ in polymer matrix. Furthermore, the uniform dispersion of high doping level $\left(10 \%\right.$ of $\left.\mathrm{TiO}_{2} \mathrm{NPs}\right)$ of $\mathrm{AR}$ with $\mathrm{TiO}_{2}$ NPs was also clarified as seen in Figure 4(c).

On the other hand, thermal stability of the new composites was studied using TGA as shown in the thermographs shown in Figure 5. Figure 5(a) represents the TGA graph of blank PS which decomposed in one step starting at $350^{\circ} \mathrm{C}$ leaving no char residue at $750^{\circ} \mathrm{C}$. However, the thermogram of AR shows three steps of mass loss, the first one below $100^{\circ} \mathrm{C}$ due to the trapped moisture (Figure 5(b)). The second was started at $173^{\circ} \mathrm{C}$ and the main decomposition one started at $273^{\circ} \mathrm{C}$ leaving char residue of $25 \%$ at $750^{\circ} \mathrm{C}$. The TGA graph of PS-FR starts with initial mass loss at $100^{\circ} \mathrm{C}$ which attributed to trapped moisture. The main mass loss starts at $288^{\circ} \mathrm{C}$ giving rise to char residue of 5\% (Figure 5(c)). This low decomposition temperature of PS-FR corresponds to decomposition of FR material in the composite. Figure 5(d) depicted the TGA graph of PS-AR composite which reflects more thermal stability compared to PS-FR. The initial mass loss related to moisture content is detected at around $100^{\circ} \mathrm{C}$ and the onset of main decomposition step shifted to $351^{\circ} \mathrm{C}$. However, the char residue was detected as $4.7 \%$ compared to PS-FR composite. The PS-AR-FR composite (Figure 5(e)) showed similar trend as PS-AR but main decomposition temperature is lowered to $305^{\circ} \mathrm{C}$ leaving enhanced char yield (9.4\%). Interestingly, the thermal stability of PS-AR- $\mathrm{TiO}_{2} \mathrm{NP}-\mathrm{FR}-10$ nanocomposite is 


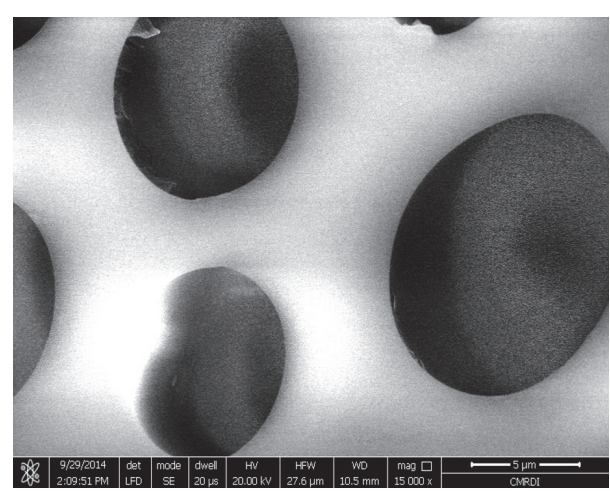

(a)

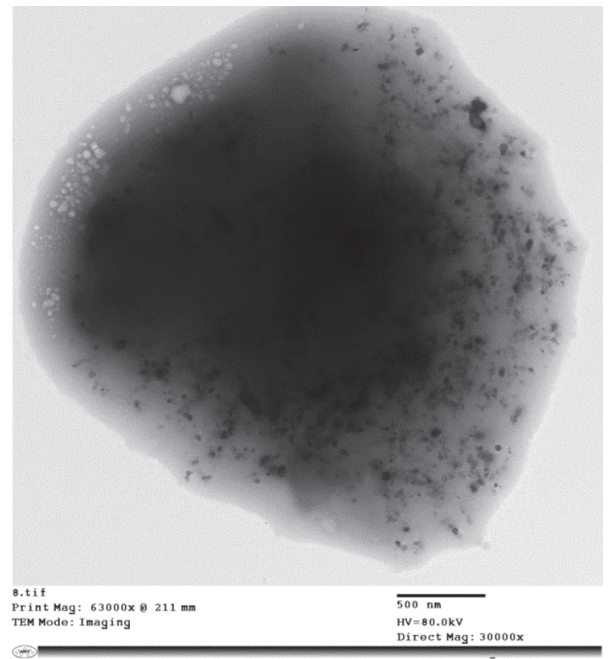

(c)

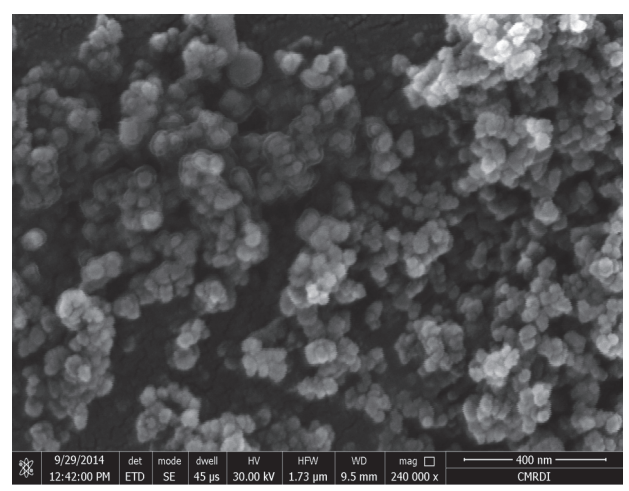

(b)

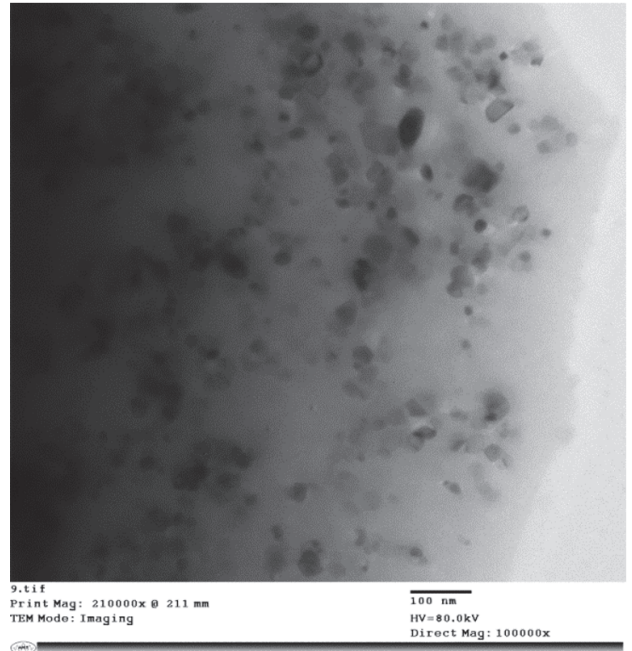

(d)

FIgURE 3: TEM images of resin (a), SEM image of $\mathrm{TiO}_{2} \mathrm{NPs}(\mathrm{b})$, and TEM images of $\mathrm{AR}-\mathrm{TiO}_{2} \mathrm{NP}-\mathrm{FR}$ nanocomposite (c) and AR-TiO $\mathrm{NP}_{2} \mathrm{FR}$ nanocomposite at high magnification $(\mathrm{d})$.

enhanced compared to previous blank and composites. The onset main decomposition step is shifted to $370^{\circ} \mathrm{C}$ compared to $350^{\circ} \mathrm{C}$ in $\mathrm{PS}$ and char residue improved to $16.6 \%$ (Figure $5(\mathrm{f})$ ). This enhanced thermal properties of PS-AR$\mathrm{TiO}_{2}$ NP-FR-10 nanocomposite stemmed from the good char barrier forming isolating decomposition polymer zone from further decomposition.

3.3. Flame Retardancy of Polystyrene Composites and Nanocomposites. The flammability properties of different PS composites were evaluated using two different tests. The first one was UL94 flame chamber according to horizontal test based on international standard IEC 60695-11-10 [32]. The flammability results of UL94 test were tabulated in Table 1. The blank PS was burned quickly giving burning rate of $46.5 \mathrm{~mm} / \mathrm{min}$. However, when FR additive was included in PS-FR composite the rate of burning was reduced to $23 \mathrm{~mm} / \mathrm{min}$ (Table 1) and flame front stopped before reaching the end of the sample. This might be due to the liberation of phosphoric acid after combustion of polymer composite leading to char layer formation, which isolates the decomposition zone of polymer from flaming one. However, when FR was replaced with AR in the composite PS-AR the rate of burning was also reduced to $19.7 \mathrm{~mm} / \mathrm{min}$. This fire retardancy property of PS-AR was due to the decomposition of AR before polymer matrix leading to formation of char layer as seen in Table 1. The rate of burning of PS-AR-FR achieved higher degree of flame retardation (62\% reduction), which might be stemmed from synergistic effect occurring in the polymer composite (Table 1). When the AR was doped with $\mathrm{TiO}_{2} \mathrm{NPs}$ in the previous composite (PS-AR-FR). The new nanocomposite PS-AR-TiO ${ }_{2} \mathrm{NP}-$ FR-5 showed improved flame retardancy behavior, where the rate of burning was found to be $13.8 \mathrm{~mm} / \mathrm{min}$ achieving $70 \%$ reduction compared to PS.

Interestingly, when the doping percent of $\mathrm{TiO}_{2} \mathrm{NPs}$ increased to 10 wt.\% in PS-AR-TiO ${ }_{2}$ NP-FR-10 the flammability has further reduced and flame stopped after $25 \mathrm{~mm}$ only from the first mark. This achieved significant reduction in rate of burning reaching to $10.7 \mathrm{~mm} / \mathrm{min}(77 \%)$ as seen in Table 1. This enhanced flame resistance properties of the nanocomposites were attributed to the synergistic effect between FR and $\mathrm{AR}-\mathrm{TiO}_{2} \mathrm{NP}$. The proposed action could be as follows. The phosphoric acid released earlier based on combustion of 


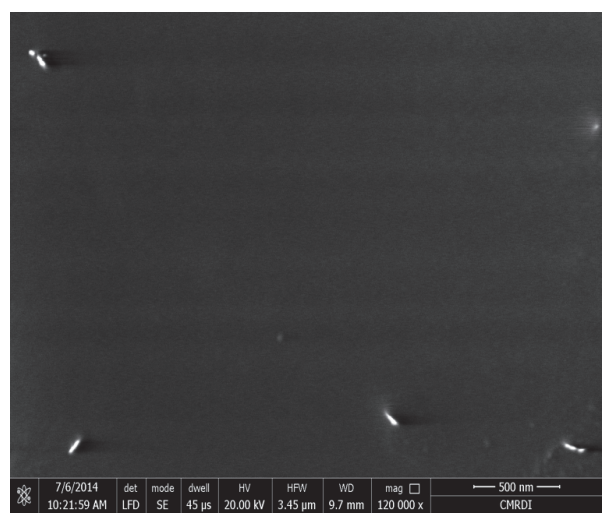

(a)

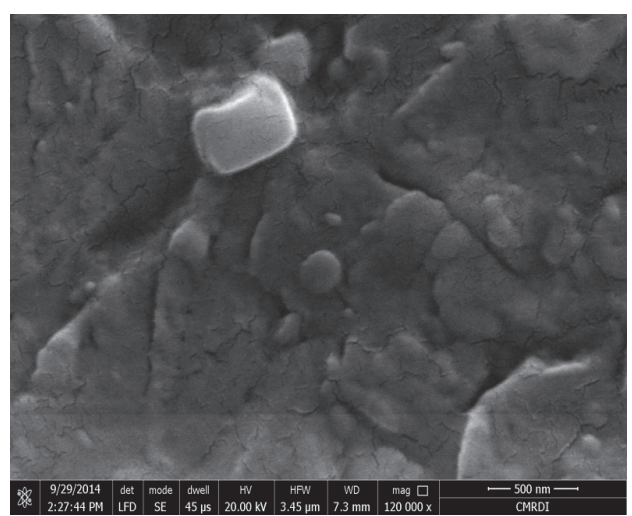

(b)

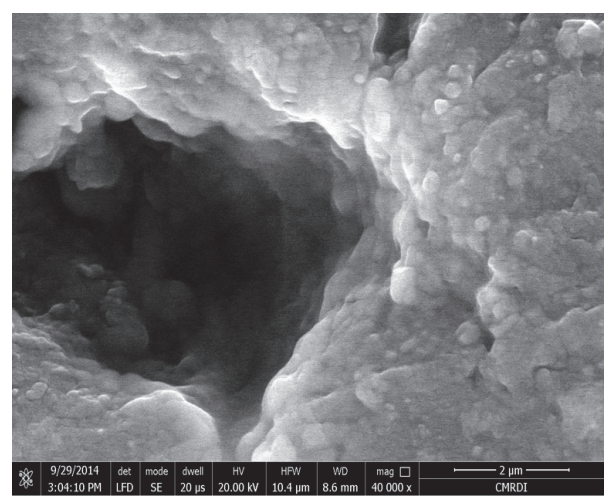

(c)

FIGURE 4: SEM images of blank PS (a), PS-AR-TiO 2 NP-FR-5 (b), and PS-AR-TiO ${ }_{2}$ NP-FR-10 (c) nanocomposites.

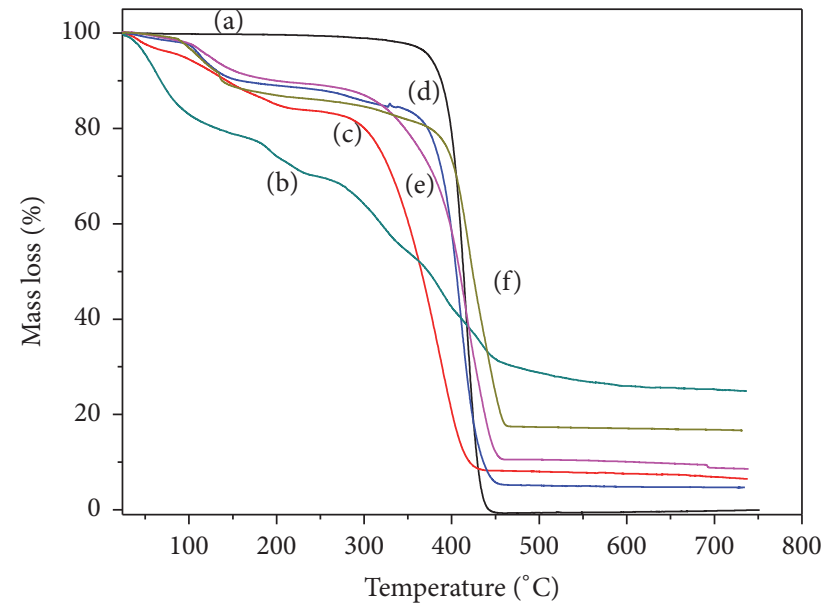

FIGURE 5: TGA curves of PS (a), AR (b), PS-FR (c), PS-AR (d), PSAR-FR (e), and PS-AR-TiO 2 NP-FR-10 (f).

the nanocomposite reacted with the AR degradation products. This reaction was catalyzed by $\mathrm{TiO}_{2} \mathrm{NPs}$ which formed strengthened char layer on the nanocomposites surface composed of new compound and effectively resists mass and heat transfer.

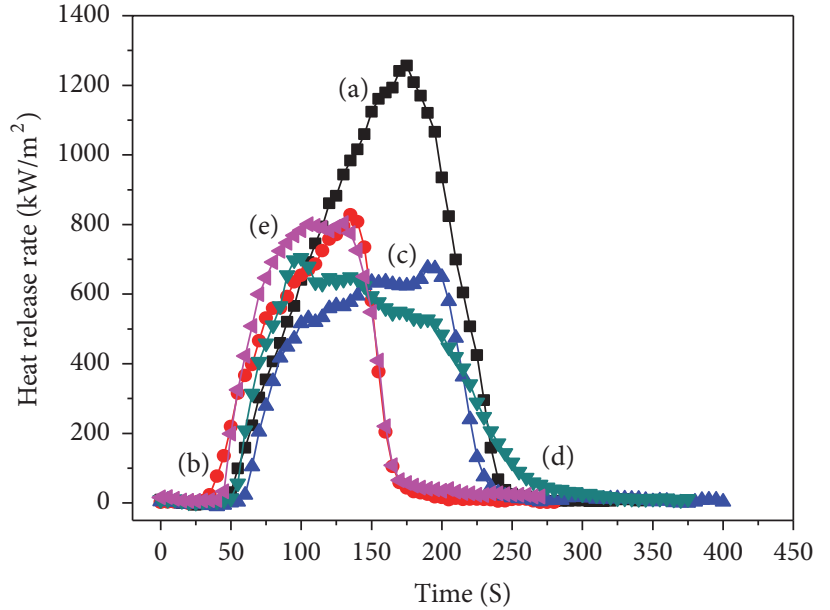

FIGURE 6: Heat release curves of PS (a), PS-FR (b), PS-AR (c), PSAR-FR (d), and PS-AR-TiO ${ }_{2}$ NP-10-FR (e).

On the other hand, Figure 6 represents the heat release curve of PS which was ignited after $47 \mathrm{sec}$ giving rise to very sharp heat release curve with PHRR of $1257 \mathrm{~kW} / \mathrm{m}^{2}$. The THR, AEHC, and AHRR were recorded as $141 \mathrm{MJ} / \mathrm{m}^{2}$, $26 \mathrm{MJ} / \mathrm{kg}$ and $562 \mathrm{~kW} / \mathrm{m}^{2}$, respectively (Table 2 and Figure 6). 
TABLE 1: Rate of burning results of PS blank and their composites.

\begin{tabular}{|c|c|c|c|}
\hline Sample code & ${ }^{(\mathrm{a})}$ Distance $(\mathrm{mm})$ & (b) Time (sec) & ${ }^{(\mathrm{c})}$ Rate of burning $(\mathrm{mm} / \mathrm{min})$ \\
\hline PS & 75 & 96.5 & 46.5 \\
\hline PS-FR & 65 & 170.5 & 23 \\
\hline PS-AR & 70 & 213.5 & 19.7 \\
\hline PS-AR-FR & 67.5 & 265 & 17.6 \\
\hline PS-AR-TiO ${ }_{2}$ NP-5-FR & 60 & 267 & 13.8 \\
\hline PS-AR-TiO 2 NP-10-FR & 25 & 140 & 10.7 \\
\hline
\end{tabular}

${ }^{(\mathrm{a})}$ Average distance burned, ${ }^{(\mathrm{b})}$ average time used for burning, and ${ }^{(\mathrm{c})}$ average rate of burning.

TABLE 2: Cone calorimetric data of the PS, PS-FR, PS-AR, PS-AR-FR, and PS-AR-TiO ${ }_{2}$ NP-FR composites.

\begin{tabular}{lccccc}
\hline Term ${ }^{[\mathrm{a}]}$ & PS & PS-FR & PS-AR & PS-AR-FR & PS-AR-TiO ${ }_{2}$ NP-10-FR \\
\hline$t_{\text {ign }}[\mathrm{s}]$ & 47 & 37 & 60 & 53 & 44 \\
PHRR $\left[\mathrm{kW} / \mathrm{m}^{2}\right]$ & 1257 & 827 & 675 & 704 & 804 \\
AHRR $\left[\mathrm{kW} / \mathrm{m}^{2}\right]$ & 562 & 289 & 253 & 309 & 340 \\
THR $\left[\mathrm{MJ} / \mathrm{m}^{2}\right]$ & 141 & 70 & 86 & 99 & 77 \\
AEHC $[\mathrm{MJ} / \mathrm{kg}]$ & 26 & 23 & 22 & 25 & 25 \\
\hline
\end{tabular}

${ }^{[\mathrm{a}]} t_{\text {ign }}$ : time to ignition; PHRR: peak heat release rate; AHR: average heat release; THR: total heat release; AEHC: average effective heat of combustion.

TABLE 3: Smoke parameters of the PS, PS-FR, PS-AR, PS-AR-FR, and PS-AR-TiO 2 NP-FR composites.

\begin{tabular}{lccccc}
\hline Term $^{[\mathrm{a}]}$ & PS & PS-FR & PS-AR & PS-AR-FR & PS-AR-TiO ${ }_{2}$ NP-10-FR \\
\hline AMLR $[\mathrm{g} / \mathrm{s}]$ & 0.054 & 0.031 & 0.028 & 0.030 & 0.033 \\
$\mathrm{CO}[\mathrm{kg} / \mathrm{kg}]$ & 0.051 & 0.053 & 0.044 & 0.056 & 0.065 \\
$\mathrm{CO}_{2}[\mathrm{~kg} / \mathrm{Kg}]$ & 1.64 & 1 & 0.92 & 0.92 & 1.22 \\
\hline
\end{tabular}

${ }^{\text {a] }}$ AMLR: average mass loss rate; $\mathrm{CO}$ : average emission of carbon monoxide; $\mathrm{CO}_{2}$ : average emission of carbon dioxide.

When organic FR was used the PS-FR composite achieved reduction in in PHRR by $34 \%\left(827 \mathrm{~kW} / \mathrm{m}^{2}\right)$ and the THR was reduced to $70 \mathrm{MJ} / \mathrm{m}^{2}$ (Table 2 ). The time required to ignite the sample is reduced to $37 \mathrm{sec}$; this is due to the decomposition of FR compound. Also the AEHC is reduced to $23 \mathrm{MJ} / \mathrm{kg}$ and AMLR is reduced to $0.031 \mathrm{~g} / \mathrm{s}$ compared to $0.054 \mathrm{~g} / \mathrm{s}$ for PS. This flame resistance behavior corresponds to the char layer formed by the liberation of phosphoric acid after combustion of polymer composite. The flammability properties of PS-AR were clearly reduced as the PHRR was found to be $675 \mathrm{~kW} / \mathrm{m}^{2}$ achieving 46\% reduction (Table 2 and Figure 6). Also, the THR and AHRR were lowered to $86 \mathrm{MJ} / \mathrm{m}^{2}$ and $253 \mathrm{~kW} / \mathrm{m}^{2}$, respectively. This is in addition to reduction in AEHC (Table 2). It is important to note that the time to ignition was extended to $60 \mathrm{sec}$. This was attributed to the action of AR in flame resistance of polymer composites. This could be proposed as, during the polymer composite heating, the AR decomposes earlier than polymer chains. This is attributed to liberation of sulphate group which triggered the formation char layer from AR [34]. This carbonaceous char structure usually contains pores which trapped the volatile combustible radicals, which then delayed the combustion as indicated in time to ignition and slow down the degradation rate of PS-AR (Table 3). This physical char layer eases up the degradation process and restricts the mass and heat transfer. This mechanism was supported by the reduction in AMLR to $0.028 \mathrm{~g} / \mathrm{s}$ compared to $0.054 \mathrm{~g} / \mathrm{s}$ for PS (Table 3).
The inclusion of FR and $\mathrm{AR}$ with equal mass ratio in PS-AR-FR composite reduced the PHRR to $704 \mathrm{~kW} / \mathrm{m}^{2}$. This value, a little higher compared to PS-AR and lower than PSFR achieving synergistic effect as depicted in digital photos, showed dense char residue (Figure 7). However, the THR was found to be $99 \mathrm{MJ} / \mathrm{m}^{2}$ and AHRR was $309 \mathrm{~kW} / \mathrm{m}^{2}$ as shown in Table 2. The time recorded to ignition is reduced to $53 \mathrm{sec}$ compared to PS-AR. This might be due to collapse of carbonaceous structure of AR which traps combustible radicals. This is clearly confirmed by AMLR value recorded as $0.030 \mathrm{~g} / \mathrm{s}$. Interestingly, when the AR was doped with $\mathrm{TiO}_{2} \mathrm{NPs}$ of an average diameter of $21 \mathrm{~nm}$ it resulted in PS-AR-TiO ${ }_{2} \mathrm{NP}-\mathrm{FR}-$ 10. The fire retardant data obtained from cone calorimeter was changed where the nanocomposite ignited faster than PS-AR and PS-AR-FR ( $44 \mathrm{sec})$. The PHRR was found to be $804 \mathrm{~kW} / \mathrm{m}^{2}$ with AHRR $340 \mathrm{~kW} / \mathrm{m}^{2}$. However, the THR was significantly reduced compared to PS-AR and PS-AR-FR composites achieving $77 \mathrm{MJ} / \mathrm{m}^{2}$ (Table 2). This change in flammability behavior of PS-AR-TiO ${ }_{2}$ NP-FR-10 could be due to the existence of cone heater irradiating $35 \mathrm{~kW} / \mathrm{m}^{2}$ during all the test time in cone test. This is in conjunction to the existence of AR doped with $\mathrm{TiO}_{2} \mathrm{NPs}$, which take part in catalyzing the decomposition process of nanocomposites. On the other hand the emission of CO in PS-FR composite is almost similar to that in PS; but the $\mathrm{CO}_{2}$ emission was reduced (Table 3). It is noteworthy to note that the emission of $\mathrm{CO}$ and $\mathrm{CO}_{2}$ was reduced in PS-AR by 14 and 44 , respectively 

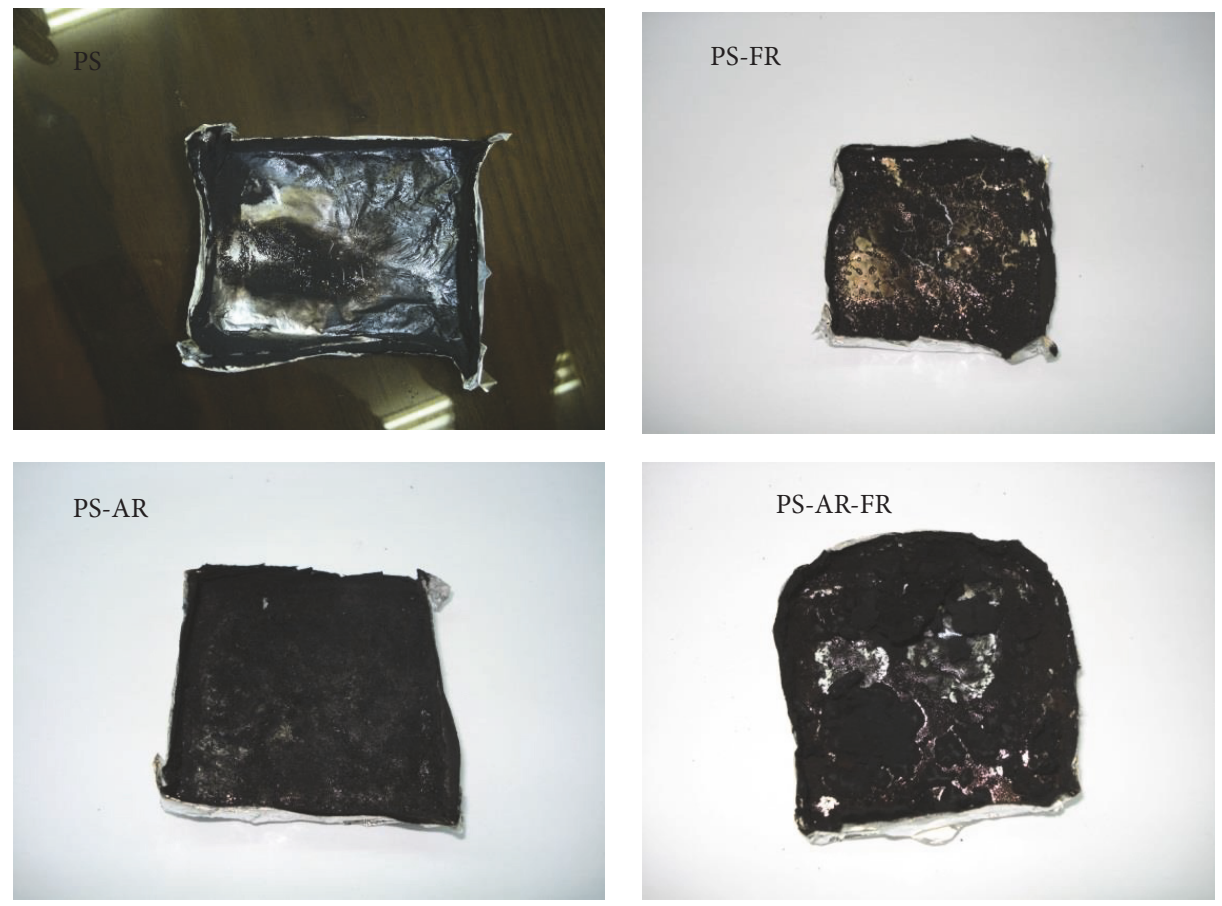

FIGURE 7: Digital photos of the char residues after cone test for the PS, PS-FR, PS-AR, and PS-AR-FR composites.

(Table 3). The emission of CO in PS-AR-FR was higher than PS indicating incomplete combustion reaction, but $\mathrm{CO}_{2}$ was reduced $(0.92 \mathrm{~kg} / \mathrm{kg})$. Interestingly, in the $\mathrm{PS}-\mathrm{AR}-\mathrm{TiO}_{2} \mathrm{NP}-$ FR-10 the emission of $\mathrm{CO}$ increased to $0.065 \mathrm{~kg} / \mathrm{kg}$ confirming incomplete combustion reaction; however the $\mathrm{CO}_{2}$ reduced $(1.22 \mathrm{~kg} / \mathrm{kg})$ compared to PS.

\section{Conclusion}

Smart and new flame retardant system has been developed for polystyrene. The flame retardancy and thermal stability of the polymer nanocomposites were improved significantly. Resin particles alone were found to be effective flame retardant of the polymer composites. Also, their use in conjunction with nanoparticles and flame retardant showed synergism flame retardant effect. Facile method for doping resin with $\mathrm{TiO}_{2} \mathrm{NPs}$ was developed. The nanoparticles doped resin was well dispersed in polymer matrix. The rate of burning, PHRR, and AMLR of the new polymer composites were reduced by 77 , 46 , and $48 \%$, respectively. This is in addition to the reduction in the emission of $\mathrm{CO}$ and $\mathrm{CO}_{2}$ gases. The proposed action of fire retardancy of resin was studied. The good flame retardancy in nanocomposites was attributed to the formation of excellent protective char layer.

\section{Conflicts of Interest}

There are no conflicts of interest regarding the publication of this paper.

\section{References}

[1] P. Kiliaris and C. D. Papaspyrides, "Polymer/layered silicate (clay) nanocomposites: an overview of flame retardancy," Progress in Polymer Science, vol. 35, no. 7, pp. 902-958, 2010.

[2] U. Bretler, M. Pellach, N. Fridman, and S. Margel, "Synthesis and characterization of poly(pentabromostyrene) micrometersized particles of narrow size distribution for flame-retardant applications," Colloid and Polymer Science, vol. 292, no. 5, pp. 1181-1189, 2014.

[3] Z. Katančić, J. Travaš-Sejdić, and Z. Hrnjak-Murgić, "Flammability and thermal properties of zeolite-filled high-impact polystyrene composites," Polymer-Plastics Technology and Engineering, vol. 53, no. 14, pp. 1487-1493, 2014.

[4] M. Brebu, T. Bhaskar, K. Murai, A. Muto, Y. Sakata, and M. A. Uddin, "The individual and cumulative effect of brominated flame retardant and polyvinylchloride (PVC) on thermal degradation of acrylonitrile-butadiene- styrene (ABS) copolymer," Chemosphere, vol. 56, no. 5, pp. 433-440, 2004.

[5] S.-Y. Lu and I. Hamerton, "Recent developments in the chemistry of halogen-free flame retardant polymers," Progress in Polymer Science, vol. 27, no. 8, pp. 1661-1712, 2002.

[6] H. Ma, J. Wang, and Z. Fang, "Cross-linking of a novel reactive polymeric intumescent flame retardant to ABS copolymer and its flame retardancy properties," Polymer Degradation and Stability, vol. 97, p. 1596, 2012.

[7] J. Li, C. Ke, L. Xu, and Y. Wang, "Synergistic effect between a hyperbranched charring agent and ammonium polyphosphate on the intumescent flame retardance of acrylonitrile-butadienestyrene polymer," Polymer Degradation and Stability, vol. 97, p. 1107, 2012. 
[8] W. Jun, L. Yi, and X. Cai, "Effect of a novel charring agent on thermal degradation and flame retardancy of acrylonitrilebutadiene-styrene," Journal of Thermal Analysis and Calorimetry, vol. 103, p. 767, 2011.

[9] M. C. Yew, N. H. Ramli Sulong, M. K. Yew, M. A. Amalina, and M. R. Johan, "Influences of flame-retardant fillers on fire protection and mechanical properties of intumescent coatings," Progress in Organic Coatings, vol. 78, pp. 59-66, 2015.

[10] M. Sabet, A. Hassan, and C. T. Ratnam, "Effect of zinc borate on flammability/thermal properties of ethylene vinyl acetate filled with metal hydroxides," Journal of Reinforced Plastics and Composites, vol. 32, p. 1122, 2013.

[11] G. Camino, N. Grassie, and I. C. McNeill, "Influence of the fire retardant, ammonium polyphosphate, on the thermal degradation of poly(methyl methacrylate)," Journal of Polymer Science Part A-Polymer Chemistry, vol. 16, no. 1, pp. 95-106, 1978.

[12] S.-H. Chiu and W.-K. Wang, "Dynamic flame retardancy of polypropylene filled with ammonium polyphosphate, pentaerythritol and melamine additives," Polymer, vol. 39, no. 10, pp. 1951-1955, 1998.

[13] N. F. Attia, M. A. Hassan, M. A. Nour, and K. E. Geckeler, "Flame-retardant materials: synergistic effect of halloysite nanotubes on the flammability properties of acrylonitrilebutadiene-styrene composites," Polymer International, vol. 63, no. 7, pp. 1168-1173, 2014.

[14] H. A. Stretz, M. W. Wootan, P. E. Cassidy, and J. H. Koo, "Effect of exfoliation on poly(styrene-co-acrylonitrile)/montmorillonite nanocomposite flammability," Polymers for Advanced Technologies, vol. 16, no. 2-3, pp. 239-248, 2005.

[15] M. Du, B. Guo, and D. Jia, “Thermal stability and flame retardant effects of halloysite nanotubes on poly(propylene)," European Polymer Journal, vol. 42, no. 6, pp. 1362-1369, 2006.

[16] S. Nie, S. Qi, M. He, and B. Li, "Synergistic effects of zeolites on a novel intumescent flame-retardant low-density polyethylene (LDPE) system," Journal of Thermal Analysis and Calorimetry, vol. 114, p. 581, 2013.

[17] J. Wang, K. Yang, and X. Zheng, "Studies on the effect of $4 \mathrm{~A}$ zeolite on the properties of intumescent flame-retardant agent filled natural rubber composites," Journal of Polymer Research, vol. 16, p. 427, 2009.

[18] J. Yi, H. Yin, and X. Cai, "Effects of common synergistic agents on intumescent flame retardant polypropylene with a novel charring agent," Journal of Thermal Analysis and Calorimetry, vol. 111, p. 725, 2013.

[19] W. Yuana, H. Chena, R. Changa, and L. Li, vol. 9, p. 248, 2011, Particuology.

[20] X. J. He, L. J. Wang, X. L. Xie, and K. Zhang, "Investigation of thermal property and flame retardancy of ABS/montmorillonite nanocomposites," Plastics Rubber and Composites, vol. 39, p. 54, 2010.

[21] A. Laachachi, E. Leroy, M. Cochez, M. Ferriol, and J. M. Lopez Cuesta, "Use of oxide nanoparticles and organoclays to improve thermal stability and fire retardancy of poly(methyl methacrylate)," Polymer Degradation and Stability, vol. 89, no. 2, pp. 344352, 2005.

[22] H. Ma, L. Tong, Z. Xu, and Z. Fang, "Synergistic effect of carbon nanotube and clay for improving the flame retardancy of ABS resin," Nanotechnology, vol. 18, p. 375602, 2007.

[23] N. Hong, Y. Pan, J. Zhan et al., "Fabrication of graphene/NiCe mixed oxide with excellent performance for reducing fire hazard of polypropylene," RSC Advances, vol. 3, no. 37, pp. 16440-16448, 2013.

[24] N. F. Attia, N. S. Abdel Eal, and M. A. Hassan, "Facile synthesis of graphene sheets decorated nanoparticles and flammability of their polymer nanocomposites," Polymer Degradation and Stability, vol. 126, p. 65, 2016.

[25] N. F. Attia, E. S. Goda, M. A. Nour, M. W. Sabaa, and M. A. Hassan, "Novel synthesis of magnesium hydroxide nanoparticles modified with organic phosphate and their effect on the flammability of acrylonitrile-butadiene styrene nanocomposites," Materials Chemistry and Physics, vol. 168, pp. 147-158, 2015.

[26] N. F. Attia, "Organic nanoparticles as promising flame retardant materials for thermoplastic polymers," Journal of Thermal Analysis and Calorimetry, vol. 127, no. 3, p. 2273, 2017.

[27] N. F. Attia, Polymers for Advanced Technologies, vol. 2, p. 1091, 2016.

[28] M. A. Hassan, H. A. Hammoda, A. M. Salah, and N. F. Attia, "Thermal analysis techniques as a primary sign for fire retardancy of new textile back-coating formulations," Journal of Industrial Textiles, vol. 39, no. 4, pp. 357-376, 2010.

[29] N. F. Attia, A. A. Abissy, and M. A. Hassan, "Novel synthesis and characterization of conductive and flame retardant textile fabrics," Polymers for Advanced Technologies, vol. 26, p. 1551, 2015.

[30] N. F. Attia, J. P. Rao, and K. E. Geckeler, "Nanodiamondpolymer nanoparticle composites and their thin films," Journal of Nanoparticle Research, vol. 16, p. 2361, 2014.

[31] M. A. Hassan, R. Kozlowski, and B. Obidzinski, "New fireprotective intumescent coatings for wood," Journal of Applied Polymer Science, vol. 110, no. 1, pp. 83-90, 2008.

[32] IEC 60695-11-10.Fire Hazard Testing- Part 11-10: Test flames$50 \mathrm{~W}$ horizontal and vertical flame test methods.

[33] ISO, "Reaction-to-fire tests - heat release, smoke production and mass loss rate - part 1: heat release rate (cone calorimeter method)," International Organization for Standardization, 2002.

[34] M. Roman and W. T. Winter, "Effect of sulfate groups from sulfuric acid hydrolysis on the thermal degradation behavior of bacterialcellulose," Biomacromolecules, vol. 5, p. 1671, 2004. 

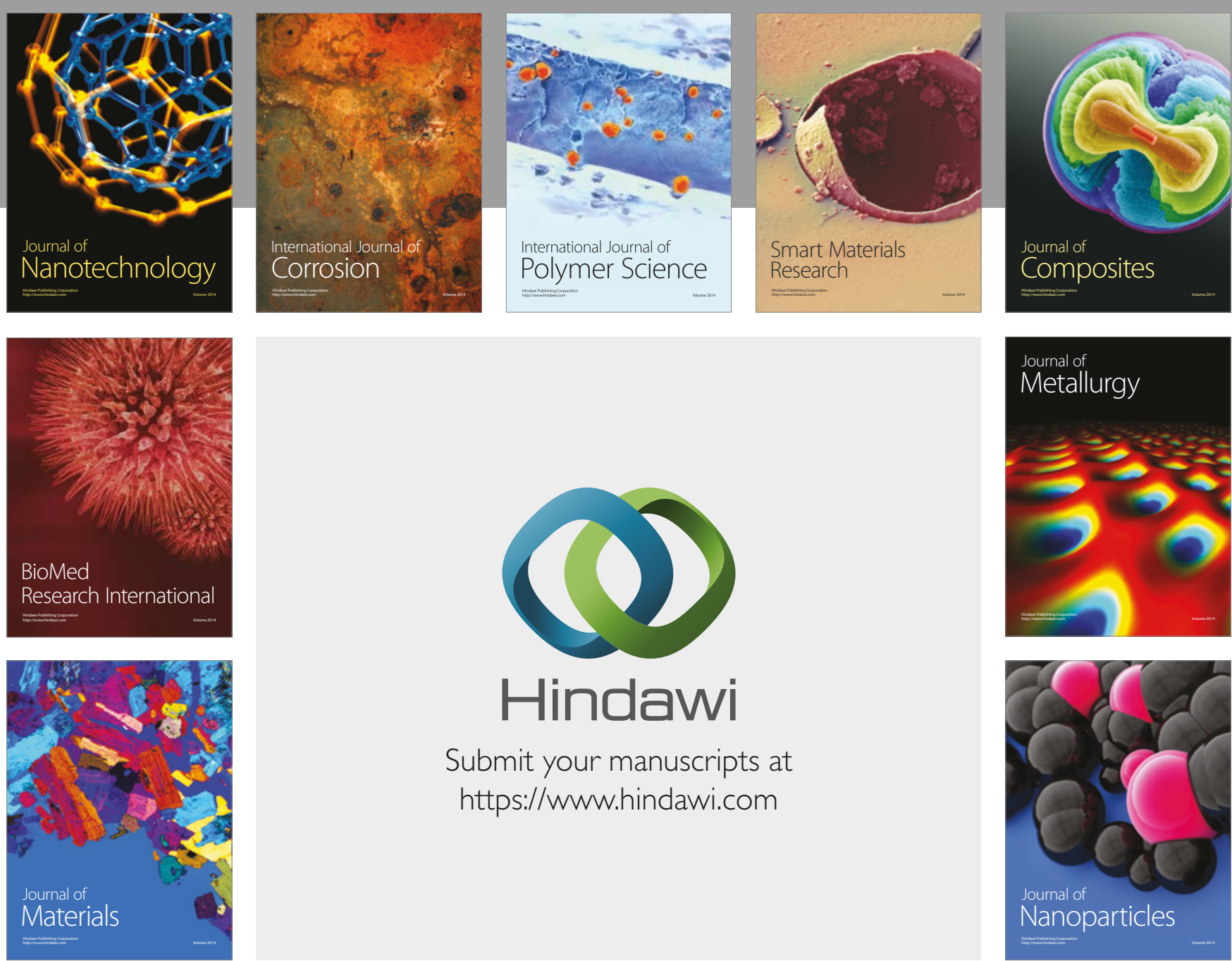

\section{Hindawi}

Submit your manuscripts at

https://www.hindawi.com
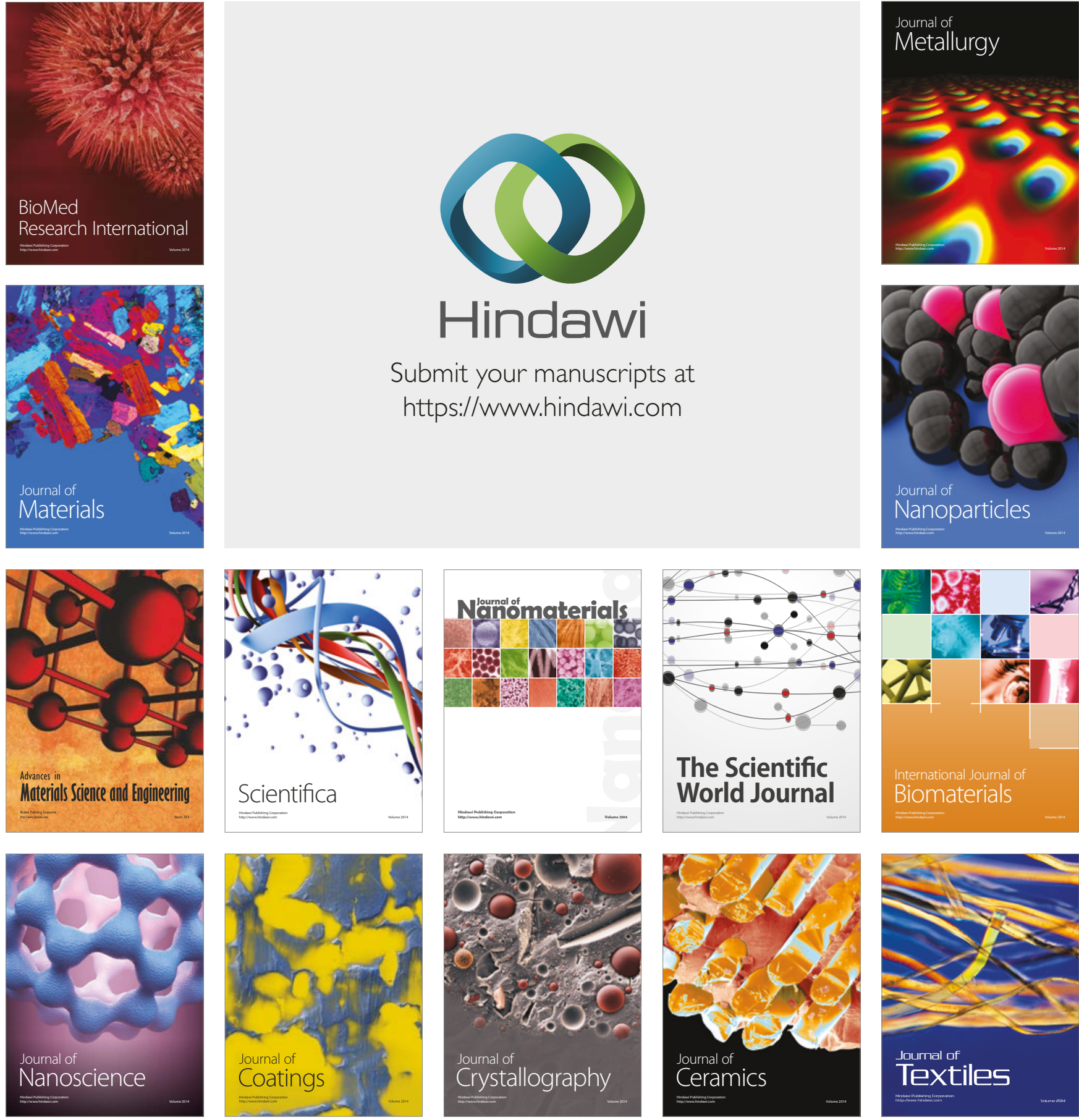

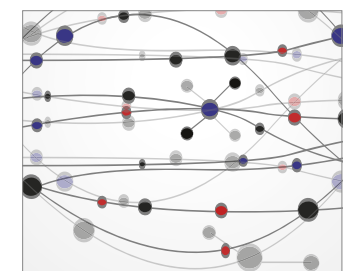

The Scientific World Journal
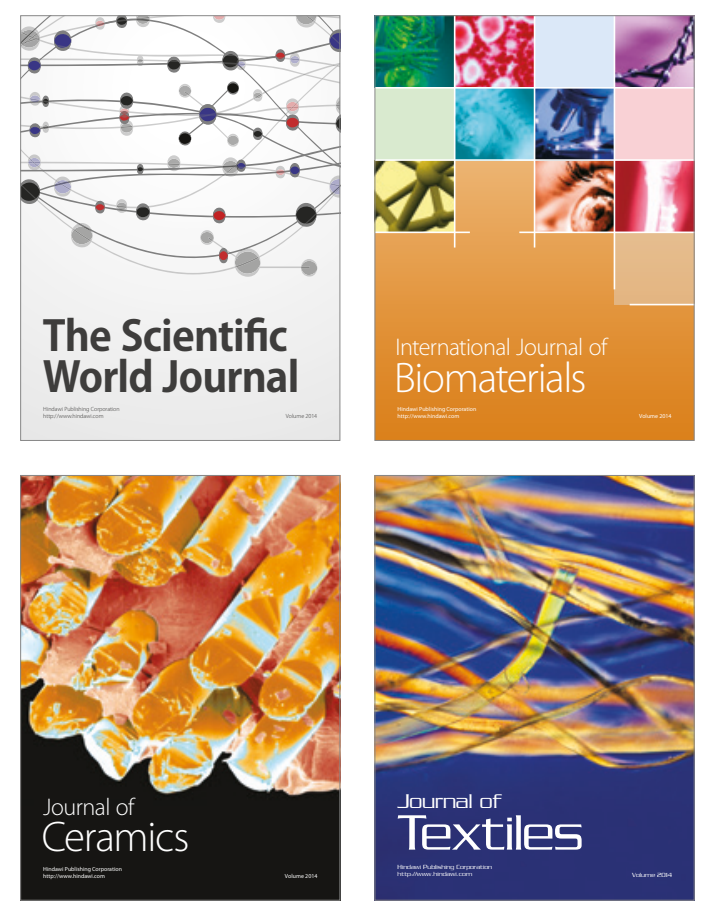